\title{
Review: ACE inhibitors delay microalbuminuria in diabetes without nephropathy and reduce mortality in diabetic nephropathy
}

Strippoli GF, Craig MC, Schena FP, et al. Role of blood pressure targets and specific antihypertensive agents used to prevent diabetic nephropathy and delay its progression. J Am Soc Nephrol 2006;17:S153-5.

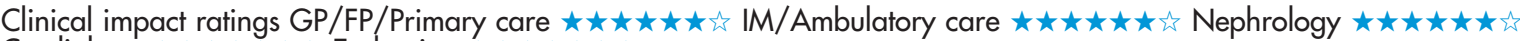

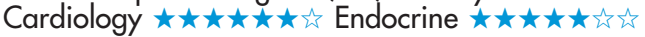

Do antihypertensive agents prevent onset of microalbuminuria in patients with diabetes without nephropathy and delay progression in patients with diabetic nephropathy?

\section{METHODS}

Data sources: Medline (1966 to September 2003), EMBASE/
Excerpta Medica (1988 to September 2003), Cochrane Central
Register of Controlled Trials (2004), reference lists, and authors in
the field.
Study selection and assessment: randomised controlled trials
(RCTs) in any language comparing an antihypertensive agent
with another antihypertensive agent or placebo in diabetic
patients with and without nephropathy. 16 RCTs ( $\mathrm{n}=8570$ ) in
diabetic patients without nephropathy and 43 RCTs ( $\mathrm{n}=7545$ ) in
diabetic patients with nephropathy met the selection criteria.
Quality assessment of individual studies was based on allocation
concealment, intention to treat analysis, loss to follow up, and
blinding.
Outcomes: onset of microalbuminuria, all cause mortality, end
stage renal disease (ESRD), doubling of serum creatinine,
progression from microalbuminuria to macroalbuminuria,
regression from microalbuminuria to normalbuminuria, cough,
headache, hyperkalaemia, and impotence.

\section{MAIN RESULTS}

Meta-analysis using a random effects model showed that angiotensin converting enzyme (ACE) inhibitors were more effective than calcium antagonists or placebo for preventing onset of microalbuminuria (table). ACE inhibitors and $\beta$ blockers did not differ for onset of microalbuminuria ( $1 \mathrm{RCT}, \mathrm{n}=299$; relative risk $1.01,95 \%$ CI 0.74 to 1.37) in diabetic patients without nephropathy. In diabetic patients with nephropathy, ACE inhibitors reduced all cause mortality more

Angiotensin converting enzyme (ACE) inhibitors and angiotensin receptor blockers (ARBs) $v$ calcium antagonists (CAs) or placebo for diabetes with and without nephropathy*

\begin{tabular}{|c|c|c|c|}
\hline Outcomes & Comparisons & $\begin{array}{l}\text { Number of } \\
\text { trials ( } n \text { ) }\end{array}$ & Relative risk $(95 \% \mathrm{Cl})$ \\
\hline \multirow{2}{*}{$\begin{array}{l}\text { Onset of } \\
\text { microalbuminuria in } \\
\text { diabetes without } \\
\text { nephropathy }\end{array}$} & $\begin{array}{l}\text { ACE inhibitors } v \\
\text { CAs }\end{array}$ & $4(1210)$ & $0.58(0.40$ to 0.84$)$ \\
\hline & $\begin{array}{l}\text { ACE inhibitors } v \\
\text { placebo }\end{array}$ & $6(3840)$ & $0.60(0.43$ to 0.84$)$ \\
\hline \multirow[t]{2}{*}{$\begin{array}{l}\text { All cause mortality in } \\
\text { diabetic nephropathy }\end{array}$} & $\begin{array}{l}\text { ACE inhibitors } v \\
\text { placebo }\end{array}$ & $20(2838)$ & 0.79 (0.63 to 0.99$)$ \\
\hline & ARBs $v$ placebo & 4 (3329) & $0.99(0.85$ to 1.17$) \dagger$ \\
\hline
\end{tabular}

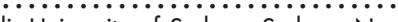
For correspondence: Dr G F Strippoli, University of Sydney, Sydney, New South Wales, Australia. gfmstrippoli@aliceposta.it

Sources of funding: Cochrane Renal Group and Australia/Europe Endeavour Scholarship. than placebo, but angiotensin receptor blockers (ARBs) did not (table). Both ACE inhibitors and ARBs reduced progression from micro to macroalbuminuria, and ARBs reduced risk of ESRD and doubling of creatinine more than placebo.

\section{CONCLUSION}

Angiotensin converting enzyme inhibitors delay onset of microalbuminuria in diabetic patients without nephropathy and reduce all cause mortality in diabetic patients with nephropathy.

Abstract and commentary also appear in ACP Journal Club

Commentary

hoosing antihypertensive treatment can be difficult because of conflicting evidence in the literature, comorbid conditions of patients, and competing drug class benefits. Strippoli et al used meta-analysis to examine whether ACE inhibitors or ARBs have advantages over other classes for cardiorenal end points in patients with diabetes. They concluded that the use of ACE inhibitors or ARBs protected the kidneys and that ACE inhibitors reduced all cause mortality. These conclusions are similar to their previous work, ${ }^{12}$ but stand in stark contrast to a meta-analysis by Casas et al that showed that the renal sparing effects of ACE inhibitors and ARBs are only present in placebo controlled trials and vanish with active comparators or when blood pressure control is taken into account. ${ }^{3}$

Conflicting conclusions can sometimes be resolved by applying the "face validity test" - that is, does the analysis include only trials that have similar populations, interventions, and outcomes? In a meta-analysis, the test for heterogeneity can determine whether the statistical properties of the trials weigh against their combination. However, trials passing this test should not automatically be combined. In the meta-analysis by Casas et al, ${ }^{3}$ about $85 \%$ of the patients came from ALLHAT, a trial that excluded patients with severe renal disease and in whom ESRD was unexpected. Such a trial should not be included in an analysis of ESRD prevention. Trial selection also influenced Strippoli et al's conclusion that ACE inhibitors but not ARBs reduce mortality in diabetes. The ACE inhibitor trials included the large cardiovascular oriented HOPE study, which excluded severe renal disease. The smaller renal oriented ARB trials only included patients with advanced renal disease-a population in which other cardioprotective therapies have failed. Both Casas et al's conclusions regarding the lack of efficacy of ACE inhibitors and ARBs beyond control of hypertension, and Strippoli et al's conclusions about the differential cardioprotective effects of ACE inhibitors and ARBs, are suspect for these reasons.

Meta-analytic techniques are a powerful method for combining the results of clinical trials. The face validity test is more powerful than the statistical test of heterogeneity in determining whether sufficiently similar trials have been included.

Philip A McFarlane, MD St Michael's Hospital Toronto, Ontario, Canada

1 Strippoli GF, Craig M, Schena FP, et al. J Am Soc Nephrol 2005;16:308191.

2 Strippoli GF, Craig M, Deeks JJ, et al. BMJ 2004;329:828

3 Casas JP, Chua W, Loukogeorgakis S, et al. Lancet 2005;366:2026-33. 